\title{
Evaluation of the pharmacokinetic and pharmacodynamic drug interactions between cilnidipine and valsartan, in healthy volunteers
}

This article was published in the following Dove Press journal:

Drug Design, Development and Therapy

8 October 2014

Number of times this article has been viewed

\author{
Jieon Lee ${ }^{1, *}$ \\ Howard Lee, ${ }^{2 *}$ \\ Kyungho Jang' \\ Kyoung Soo $\mathrm{Lim}^{3}$ \\ Dongseong Shin' \\ Kyung-Sang Yu' \\ 'Department of Clinical Pharmacology \\ and Therapeutics, Seoul National \\ University College of Medicine and \\ Hospital, Seoul, Republic of Korea; \\ ${ }^{2}$ Clinical Trials Center, Seoul National \\ University Hospital, Seoul, Republic \\ of Korea; ${ }^{3}$ Department of Clinical \\ Pharmacology and Therapeutics, \\ CHA University School of Medicine \\ and CHA Bundang Medical Center, \\ Seongnam, Republic of Korea \\ *These authors contributed equally \\ to this work
}

Purpose: Although cilnidipine and valsartan are widely coadministered to patients with hypertension, their drug-drug interaction potential has not been investigated. This study compared the pharmacokinetic (PK), pharmacodynamic (PD), and tolerability profiles of cilnidipine and valsartan, both alone and in combination, in healthy male subjects.

Patients and methods: Fifty-four subjects, enrolled into an open-label, single-dose, three-treatment, three-period crossover study, randomly received cilnidipine (10 mg), valsartan (160 mg), or both according to one of six sequences. Blood samples were collected at baseline and up to 24 hours after drug administration in each period. Plasma concentrations of cilnidipine and valsartan were determined by liquid chromatography with tandem mass spectrometry. Maximum plasma concentration $\left(\mathrm{C}_{\max }\right)$ and area under the concentration-time curve from 0 to the last measurable time $\left(\mathrm{AUC}_{\text {last }}\right)$ were estimated using a noncompartmental method. Tolerability was evaluated by assessing adverse events (AEs), vital signs, electrocardiograms, and clinical laboratory tests. Blood pressure was also measured for PD assessment.

Results: A total of 51 subjects completed the study. The PK profile of cilnidipine was not significantly affected by coadministered valsartan; the geometric mean ratio and $90 \%$ confidence interval $(90 \% \mathrm{CI})$ of $\mathrm{AUC}_{\text {last }}$ for cilnidipine with and without valsartan was $1.04(0.98-1.10)$. Likewise, cilnidipine did not affect the PK of valsartan; the geometric mean ratio $(90 \% \mathrm{CI})$ of $\mathrm{AUC}_{\text {last }}$ for valsartan with and without cilnidipine was 0.94 (0.83-1.07). Coadministration of cilnidipine and valsartan reduced blood pressure in an additive way. No serious AEs were reported, and both cilnidipine and valsartan were well tolerated.

Conclusion: Coadministered cilnidipine and valsartan do not cause a significant PK or PD interaction, and they are well tolerated.

Keyword: antihypertensive drugs

\section{Introduction}

Hypertension requires strict blood pressure control to lower the risk for cardiovascular disease or kidney failure. ${ }^{1}$ The combination of two or more antihypertensive agents having different mechanisms can reliably reduce blood pressure. ${ }^{2}$ Combination therapy also minimizes the risk for adverse effects, prevents major cardiovascular diseases and end-organ damage, and increases drug compliance. ${ }^{3,4}$ For example, angiotensin II receptor blockers (ARBs) and calcium channel blockers (CCBs) have been widely coadministered to treat hypertension when ARB or CCB alone was insufficient in lowering blood pressure. . $^{2,6}$

Cilnidipine is a dihydropyridine CCB that acts on the L-type calcium channel of blood vessels by blocking incoming calcium and suppressing the contraction
Correspondence: Kyung-Sang Yu Department of Clinical Pharmacology and Therapeutics, Seoul National University College of Medicine and Hospital, I0I Daehak-ro, Jongno-gu, Seoul I I0-799, Korea Tel +82220721920

Fax +82 27429252

Email ksyu@snu.ac.kr 
of blood vessels, thereby reducing blood pressure. ${ }^{7}$ Cilnidipine also works on the N-type calcium channel located at the end of the sympathetic nerve, inhibiting the emission of norepinephrine and suppressing the increase in stress blood pressure. ${ }^{7,8}$ Once-daily administration of cilnidipine has been shown to decrease blood pressure safely and effectively, without excessive blood pressure reduction or tachycardia. ${ }^{9}$

Valsartan is one of the most widely used ARBs. Valsartan lowers blood pressure by antagonizing the renin-angiotensin-aldosterone system, selectively competing with the angiotensin II receptor subtype (AT1) and preventing the angiotensin II-mediated increase in blood pressure. Valsartan can lower blood pressure for 24 consecutive hours, ${ }^{10}$ which renders once-daily administration of valsartan effective for the treatment of hypertension. ${ }^{10,11}$

Any combination therapy must be evaluated to ensure that it does not exhibit clinically significant drug-drug interactions, which may decrease drug efficacy and/or increase the risk of adverse events. Although cilnidipine has been frequently prescribed with valsartan in clinical practice ${ }^{2}$, no formal study has been performed to investigate the drug-drug interaction potential between them, to the best of our knowledge. Because a fixed dose combination drug of cilnidipine and valsartan has been under development by Ildong Pharmaceuticals, Ltd, Seoul, Korea, the first step was to conduct an in vivo drug-drug interaction study. Based on this understanding, the objective of the present study (ClinicalTrials.gov registry number: NCT01838967) was to evaluate the pharmacokinetic (PK), pharmacodynamic (PD), and tolerability profiles of cilnidipine (Cinalong ${ }^{\circledR}$; Boryung Co, Ltd, Seoul, Korea) and valsartan (Diovan ${ }^{\circledR}$; Novartis Pharmaceuticals Corp, Basel, Switzerland) when administered alone or in combination. To this end, a singledose PK and PD interaction study of cilnidipine and valsartan was performed in healthy male subjects.

\section{Materials and methods Subjects}

Eligible subjects were Korean healthy male volunteers (ages 20 to 40 years) whose body mass index (BMI) was in the range of $18.5-25.0 \mathrm{~kg} / \mathrm{m}^{2}$. Subjects were included if they were in good health, based on previous medical history, physical examination, resting blood pressure, 12-lead electrocardiography (ECG), serology (hepatitis B surface antigen, anti-hepatitis $\mathrm{C}$ virus, and anti-human immunodeficiency virus antibody), and urinary drug screening (amphetamine, cocaine, barbiturate, benzodiazepines, and opioids) that was obtained within 4 weeks of the first administration of the study drug. Subjects were excluded if there was evidence or a history of any of the following: clinically significant hepatic, gastrointestinal, renal, neurologic, immunologic, hematologic, oncologic, psychiatric, or cardiovascular diseases; drug allergies or drug abuse; the use of any prescription medication during the 14 days before the first dosing; participation in clinical trials of any drug within 60 days prior to this study; heavy smoking within 2 months of the study; or heavy alcohol drinking or blood donation within 1 month prior to the start of the study. Subjects were also excluded if their sitting blood pressure fell in the following ranges during the screening procedure: systolic blood pressure $(\mathrm{SBP})<100 \mathrm{mmHg}$ or $>150 \mathrm{mmHg}$; diastolic blood pressure $(\mathrm{DBP})<60 \mathrm{mmHg}$ or $>100 \mathrm{mmHg}$.

\section{Study design and procedures}

This study was conducted using a randomized, open-label, single-center, single-dose, three-treatment, three-period, six-sequence crossover design. All eligible subjects were admitted to the Clinical Trial Center at Seoul National University Hospital, Seoul, Korea by 9 pm on the day before the administration of the study drug in each period (ie, day -1 , 7, and 14).

Subjects were randomly allocated to one of six sequences to receive cilnidipine $(10 \mathrm{mg})$ alone, valsartan $(160 \mathrm{mg})$ alone, or cilnidipine $(10 \mathrm{mg})$ and valsartan $(160 \mathrm{mg})$ in each period (Figure 1). Two adjacent periods were separated by a 7- day "washout". The doses of cilnidipine and valsartan used in this study were determined based on the recommended doses on the drug label, to treat hypertension. ${ }^{1}$ After overnight fasting, the study drugs were administered with $240 \mathrm{~mL}$ of water, at the same time approximately, on the morning of all treatment days.

This study (ClinicalTrials.gov registry number: NCT01838967) was conducted in compliance with the ethical principles of the Declaration of Helsinki (6th revised), ${ }^{12}$ the International Conference on Harmonization Good Clinical Practice Guidelines, and local laws and regulations. All subjects provided written informed consent before being screened for eligibility.

\section{Determination of cilnidipine and valsartan plasma concentrations}

Blood samples were obtained at 0 (ie, predose), 0.5, 1, 2, $2.5,3,4,5,6,8,12$, and 24 hours after drug administration 


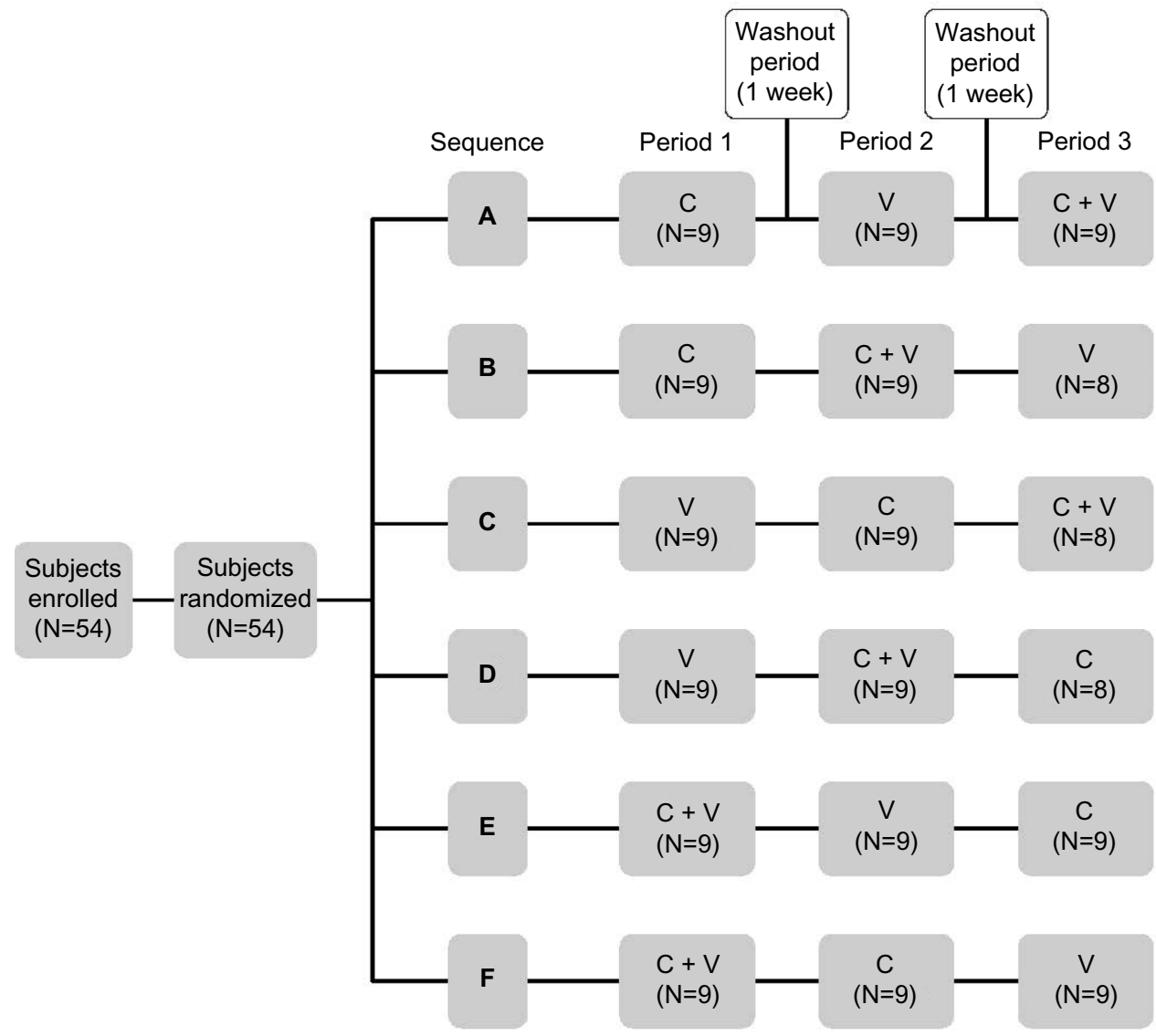

Figure I Study design.

Notes: $\mathrm{C}=$ cilnidipine at $10 \mathrm{mg} ; \mathrm{V}=$ valsartan at $160 \mathrm{mg}$. Nine subjects were allocated to each sequence group.

in each period. Collected blood was immediately transferred into a heparinized tube and temporarily stored on ice. The tubes were then centrifuged for 10 minutes at $3,000 \mathrm{rpm}$ below $4^{\circ} \mathrm{C}$. Plasma was aliquoted and stored below $-70^{\circ} \mathrm{C}$.

Plasma concentrations of cilnidipine and valsartan were determined using high-performance liquid chromatography (LC-20AD; Shimadzu, Kyoto, Japan) coupled with tandem mass spectrometry (Applied Biosystems ${ }^{\circledR}$ API4000; Life Technologies Corp, Foster City, CA, USA). The lower limit of quantitation for cilnidipine and valsartan was 0.1 and $20 \mathrm{ng} / \mathrm{mL}$, respectively. The calibration curves were linear, in the range of $0-50 \mathrm{ng} / \mathrm{mL}$ for cilnidipine and $20-2,000 \mathrm{ng} / \mathrm{mL}$ for valsartan. Intraday accuracy ranged from $87.9 \%-98.0 \%$ and $99.0 \%-105.7 \%$ for cilnidipine and valsartan, respectively. Likewise, interday accuracy ranged from $95.8 \%-101.2 \%$ and $97.4 \%-105.5 \%$ for cilnidipine and valsartan, respectively. The intraday and interday precisions ( $\%$ coefficient of variation) were $1.4 \%-9.3 \%$ and $1.8 \%-3.8 \%$ for cilnidipine and valsartan, respectively.

\section{PK analysis}

PK parameters were derived using a noncompartmental analysis, implemented in Phoenix WinNonlin (Version 6.3; Certara, St Louis, MO, USA). The area under the plasma concentration-time curve from zero to the last measurable time point $\left(\mathrm{AUC}_{\text {last }}\right)$ was calculated using the linear-up and log-down trapezoidal method. The area under the plasma concentration-time curve from time zero to infinite time $\left(\mathrm{AUC}_{\text {inf }}\right)$ was calculated as the sum of the $\mathrm{AUC}_{\text {last }}$ and the last quantifiable concentration divided by the slope of the final decline portion of the individual log-linear concentrationtime curve. The maximum plasma concentration $\left(\mathrm{C}_{\max }\right)$ and the time to reach the maximum plasma concentration $\left(t_{\max }\right)$ were taken directly from the observed values. The apparent clearance was calculated by dividing the dose by the AUC.

\section{Tolerability and PD assessments}

Tolerability was assessed in all subjects who received at least one or more doses of the study drugs. Adverse events (AEs), 
physical examinations, vital signs, laboratory tests, and 12-lead ECG were assessed during the entire study period. SBP and DBP were measured after a 3-minute rest, in the sitting position, at the following times: before drug administration and at $2,4,6,12$, and 24 hours after drug administration.

\section{Statistical analysis}

All statistical analyses were performed using the Statistical Package for the Social Sciences software (Version 21.0; SPSS Korea Data Solution Inc., Seoul, Korea). For continuous data, arithmetic mean, standard deviation,

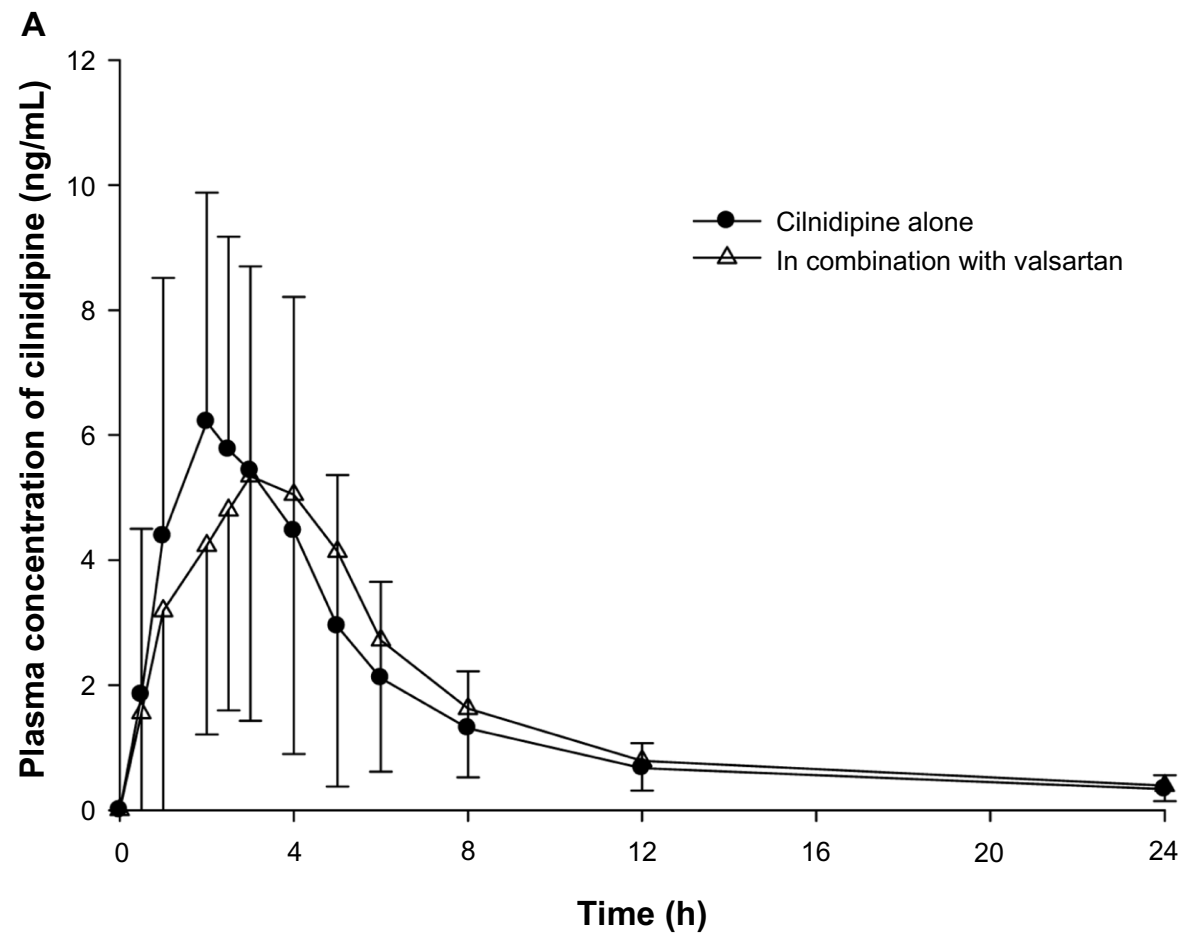

B

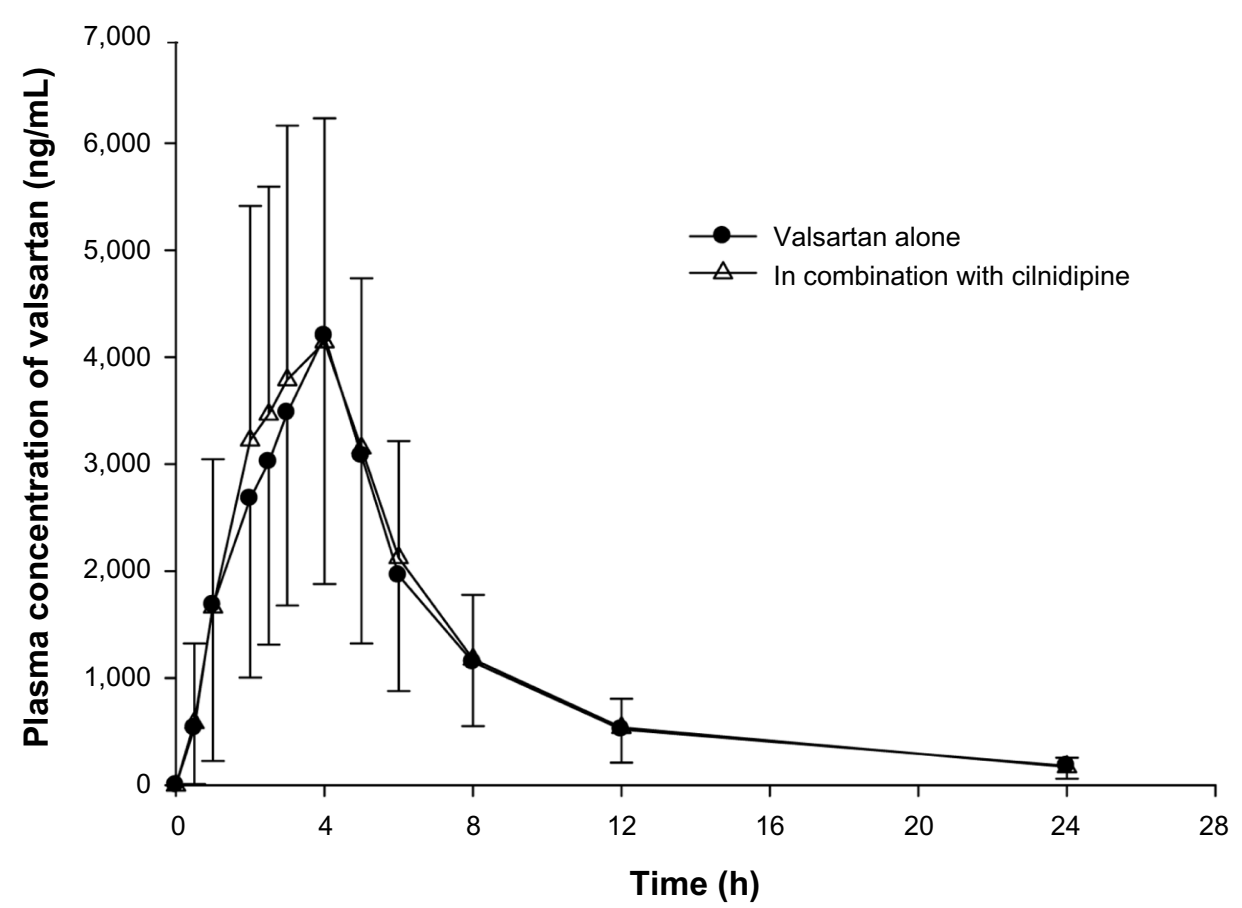

Figure 2 Mean plasma concentration-time profiles of cilnidipine (A) and valsartan (B). Note: The error bar denotes the standard deviation. 
median, and maximum and minimum values were calculated. The number of AEs and subjects experiencing them were counted by treatment group. The effect of coadministration on the PK parameters was assessed using the geometric mean ratio (GMR) of combination treatment to cilnidipine or valsartan alone, for $\mathrm{C}_{\max }, \mathrm{AUC}_{\text {last }}$, and $\mathrm{AUC}_{\text {inf }}$. To this end, the natural logarithm-transformed $\mathrm{C}_{\text {max }}, \mathrm{AUC}_{\text {last }}$, and $\mathrm{AUC}_{\text {inf }}$ were fit using a linear mixed effects model, where sequence, period, and treatments were fixed effects, and subject nested for sequence was a random effect. To compare the changes in SBP and DBP among treatment groups, a repeated measure analysis of variance (RM-ANOVA) was conducted. Probability values of less than 0.05 were considered statistically significant.

\section{Results}

\section{Study subjects}

A total of 54 healthy male subjects were enrolled in this study, three of whom dropped out prior to completion of the study (Figure 1); two subjects withdrew consent during the washout period between periods 2 and 3, and one subject was excluded due to mild prolongation in the pulse rate (PR) interval on ECG, identified right before the administration of cilnidipine alone in period 3 . The mean \pm standard deviation for age and BMI was $27.4 \pm 4.1$ years and $22.6 \pm 1.7 \mathrm{~kg} / \mathrm{m}^{2}$, respectively, which were not significantly different among sequence groups.

\section{PK assessments}

Effect of valsartan on the PK profile of cilnidipine

The PK analysis population consisted of 51 subjects who completed the entire study as planned. The mean plasma concentration-time profiles of cilnidipine after a single oral administration at $10 \mathrm{mg}$ did not significantly differ when it was administered alone and when it was coadministered with valsartan $160 \mathrm{mg}$ (Figure 2A and Table 1). For example, the total exposure to cilnidipine was comparable, ie, the GMR ( $90 \%$ confidence interval [CI]) of $\mathrm{C}_{\max }$ and $\mathrm{AUC}_{\text {last }}$ for cilnidipine with and without valsartan was 0.91 (0.83-1.00) and 1.04 (0.98-1.10), respectively, although cilnidipine was absorbed slightly slower when it was coadministered with valsartan than when it was administered alone (median $\mathrm{t}_{\max }: 2.0$ vs 2.5 hours for cilnidipine alone and in combination, respectively) (Table 1).

\section{Effect of cilnidipine on the PK of valsartan}

The concentration-time profiles of valsartan $160 \mathrm{mg}$ with or without cilnidipine $10 \mathrm{mg}$ were not significantly different (Figure 2B and Table 1). The GMR (90\% CI) for valsartan with and without coadministered cilnidipine was 0.95 (0.81-1.12) and 0.94 (0.83-1.07), respectively, for $\mathrm{C}_{\max }$ and $\mathrm{AUC}_{\text {last }}($ Table 1).

\section{Pharmacodynamic assessments}

In all treatment groups, both SBP and DBP were decreased after a single administration of cilnidipine or valsartan alone and in combination. The greatest decreases in both SBP and DBP were seen at approximately 6 hours after study drug administration, when coadministered cilnidipine and valsartan resulted in a 2.9-fold significantly larger decrease in SBP (14.7 vs 5.0 mmHg for SBP) (Figure 3A) and a 2.1-fold significantly larger decrease in DBP than did cilnidipine alone (16.3 vs $7.9 \mathrm{mmHg}$ for DBP) (Figure 3B) $(P<0.001$, RM-ANOVA test).

Table I Pharmacokinetic parameters of cilnidipine and valsartan after a single oral administration of each drug alone or in combination

\begin{tabular}{|c|c|c|c|c|c|c|}
\hline \multirow[t]{2}{*}{ Parameters } & \multicolumn{3}{|l|}{ Cilnidipine } & \multicolumn{3}{|l|}{ Valsartan } \\
\hline & Alone & $\begin{array}{l}\text { In combination } \\
\text { with valsartan }\end{array}$ & $\begin{array}{l}\text { Geometric } \\
\text { mean ratio }^{a} \\
(90 \% \mathrm{CI})\end{array}$ & Alone & $\begin{array}{l}\text { In combination } \\
\text { with cilnidipine }\end{array}$ & $\begin{array}{l}\text { Geometric } \\
\text { mean ratio } \\
(90 \% \mathrm{Cl})\end{array}$ \\
\hline $\mathrm{t}_{\max }(\mathrm{h})$ & $2(0.5-5)$ & $2.5(0.5-5.02)$ & & $3(1-6)$ & $4(I-5.02)$ & \\
\hline $\mathrm{C}_{\max }(\mathrm{ng} / \mathrm{mL})$ & $8.9 \pm 4.2$ & $8.3 \pm 4.5$ & 0.91 (0.83-I.00) & $4,754.9 \pm 2,219.4$ & $4,612.6 \pm 2,302.4$ & $0.95(0.8 I-I .12)$ \\
\hline $\mathrm{AUC}_{\text {last }}(\mathrm{ng} \cdot \mathrm{h} / \mathrm{mL})$ & $37.0 \pm 17.9$ & $38.7 \pm 19.7$ & $1.04(0.98-1.10)$ & $27,103.4 \pm 12,754.1$ & $25,864.5 \pm|2,6| \mid .0$ & $0.94(0.83-1.07)$ \\
\hline $\mathrm{AUC}_{\text {inf }}(\mathrm{ng} \cdot \mathrm{h} / \mathrm{mL})$ & $41.2 \pm 20.4$ & $43.1 \pm 22.5$ & I.04 (0.98-I.II) & $28,565.3 \pm 13,4 \mid 7.2$ & $27,498.1 \pm 13,676.0$ & $0.95(0.84-1.07)$ \\
\hline CL/F (L/h) & $304.7 \pm 147.5$ & $292.9 \pm 143.2$ & & $6.9 \pm 3.3$ & $7.6 \pm 5.1$ & \\
\hline
\end{tabular}

Notes: $\mathrm{N}=5 \mathrm{I}$. Data are mean \pm standard deviation except for $\mathrm{t}_{\max }$, for which median (minimum - maximum) is presented. ${ }^{\mathrm{a}} \mathrm{Geometric}$ mean ratio of combination treatment to cilnidipine or valsartan alone.

Abbreviations: $\mathrm{AUC}_{\text {inf }}$, area under the plasma concentration-time curve from time zero extrapolated to infinity; $A \cup C_{\text {last }}$, area under the plasma concentration-time curve to the last observation; $C_{\max }$, maximum plasma concentration; $\mathrm{Cl}$, confidence interval; $\mathrm{CL} / \mathrm{F}$, apparent clearance; $t_{\max }$, time to reach $\mathrm{C}_{\max }$. 

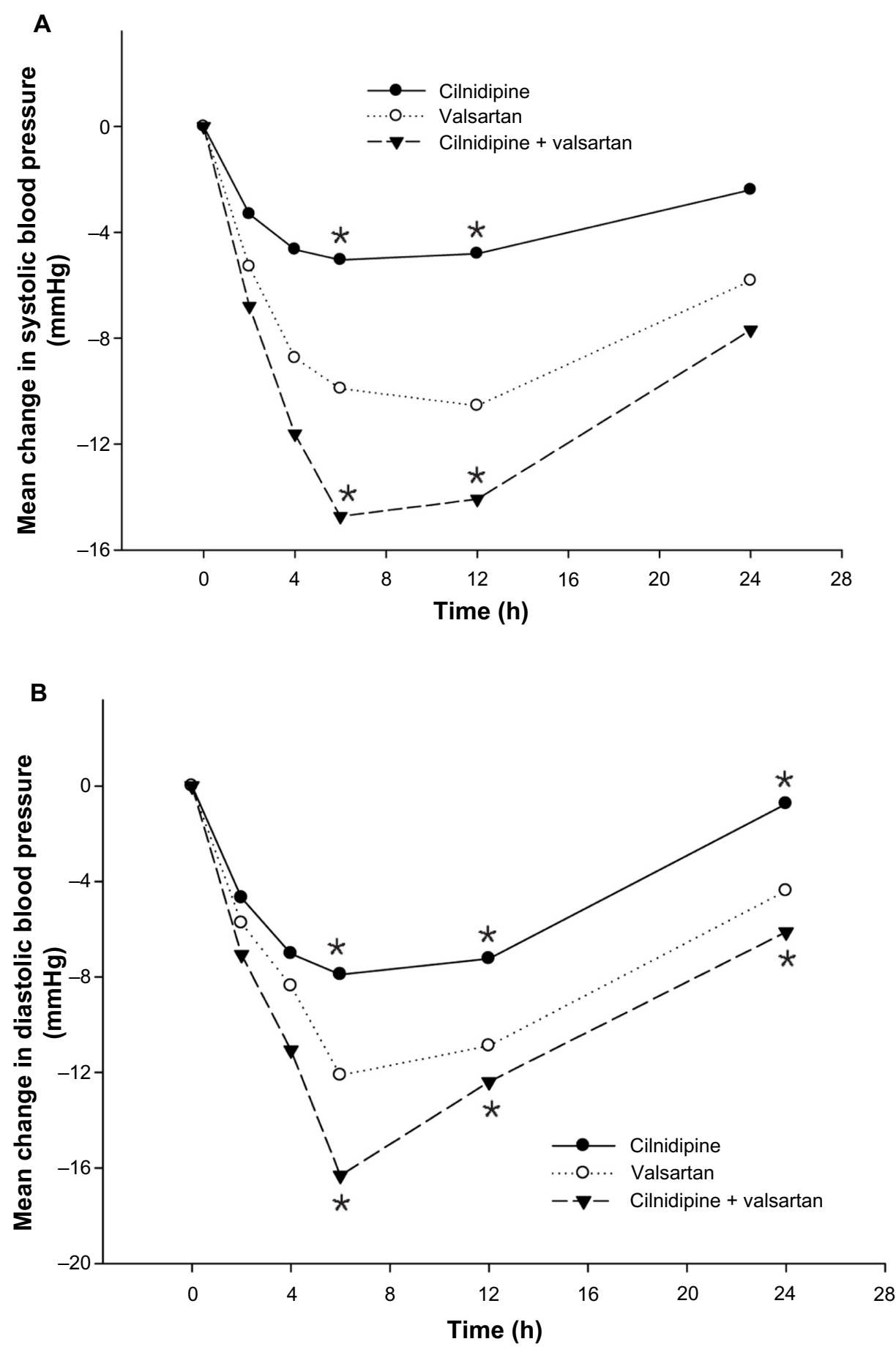

Figure 3 Mean changes from baseline in systolic (A) and diastolic (B) blood pressure after a single oral administration of cilnidipine alone, valsartan alone, and cilnidipine and valsartan in combination.

Note: $* P<0.00$ I for systolic blood pressure (at $4 \mathrm{~h}$ and $12 \mathrm{~h}$ ) and diastolic blood pressure (at $4 \mathrm{~h}, 12 \mathrm{~h}$, and $24 \mathrm{~h}$ ) after administration of cilnidipine alone and after coadministration, by a repeated measure analysis of variance.

\section{Tolerability assessments}

Both cilnidipine and valsartan were well tolerated. During the entire study period, a total of 24 AEs were reported in 15 subjects. All AEs were mild in severity and resolved without any treatment, except for one subject who was treated with ointment once because of acne. No serious AE was reported. Thirteen AEs were considered "possibly related" to the study drug, including dizziness $(\mathrm{n}=4)$, nausea $(\mathrm{n}=2)$, headache or head discomfort $(\mathrm{n}=3)$, and one case each of diarrhea, cold sweat, somnolence, and increased tendency to bruise (Table 2). 
Table 2 Summary of adverse events by treatment group

\begin{tabular}{llll}
\hline Adverse events & $\begin{array}{l}\text { Cilnidipine } \\
(\mathbf{n}=53)\end{array}$ & $\begin{array}{l}\text { Valsartan } \\
(\mathbf{n}=53)\end{array}$ & $\begin{array}{l}\text { Cilnidipine + } \\
\text { valsartan } \\
(\mathbf{n}=53)\end{array}$ \\
\hline $\begin{array}{l}\text { Considered related } \\
\text { to the study drug } \\
\text { Nausea }\end{array}$ & & $2(2)$ & \\
$\begin{array}{l}\text { Diarrhea } \\
\text { Head discomfort }\end{array}$ & $\mathrm{I}(\mathrm{I})$ & $\mathrm{I}(\mathrm{I})$ & $\mathrm{I}(\mathrm{I})$ \\
$\begin{array}{l}\text { Dizziness } \\
\text { Headache }\end{array}$ & & $\mathrm{I}(\mathrm{I})$ & $\mathrm{I}(\mathrm{I})$ \\
$\begin{array}{l}\text { Somnolence } \\
\text { Cold sweat } \\
\text { Increased tendency } \\
\text { to bruise }\end{array}$ & & $\mathrm{I}(\mathrm{I})$ \\
$\begin{array}{l}\text { Considered unrelated } \\
\text { to the study drug }\end{array}$ & $8(4)$ & $\mathrm{I}(\mathrm{I})$ & $\mathrm{I}(\mathrm{I})$ \\
\begin{tabular}{l} 
Total \\
\hline
\end{tabular} & $9(5)$ & $7(6)$ & $8(7)$ \\
\hline
\end{tabular}

Note: Data are number of adverse events (number of subjects with adverse events).

\section{Discussion}

This study shows that cilnidipine and valsartan do not exert a significant PK drug interaction when coadministered in healthy male subjects. The evidence is that the point estimates of the GMR with and without the coadministered drug for the PK parameters, including $\mathrm{C}_{\max }, \mathrm{AUC}_{\text {last }}$, and $\mathrm{AUC}_{\text {inf }}$, were close to 1 , and all of their $90 \%$ confidence intervals fell entirely within the conventional bioequivalence range of 0.8-1.25 (Table 1 and Figure 2). Moreover, coadministration of cilnidipine and valsartan reduced blood pressure in an additive way, confirming that neither adversely affected the other's blood pressure-lowering effect (Figure 3). In addition, cilnidipine and valsartan, both alone and in combination, were well tolerated, despite that they were administered at relatively high doses $(10 \mathrm{mg}$ and $160 \mathrm{mg}$ for cilnidipine and valsartan, respectively). To support this notion, no serious AE occurred, and all of the AEs considered related to the study drugs, including head discomfort, dizziness, headache, and somnolence, are well described with the use of cilnidipine and valsartan. ${ }^{11,13,14}$

Our study results are consistent with the findings of in vitro studies that identified different elimination pathways for cilnidipine and valsartan, ${ }^{15,16}$ thereby decreasing the likelihood of PK drug interaction between them. Cilnidipine is primarily metabolized by cytochrome $\mathrm{P} 450$ (CYP3A4), and to a lesser extent by CYP2C19. ${ }^{15}$ However, approximately $80 \%$ of valsartan is excreted as unchanged parent drug, with the remaining drug being primarily metabolized by CYP2C19. ${ }^{15}$ In addition, organic anion transporter-mediated excretion of valsartan through the bile was recently reported, ${ }^{16}$ but such a mechanism has never been reported for dihydropyridine compounds such as cilnidipine.

In all of the treatment groups, a maximal blood pressurelowering effect was seen around 4-6 hours postdose, whereas the $\mathrm{t}_{\text {max }}$ was observed much earlier, ie, 2-2.5 hours for cilnidipine and 3-4 hours for valsartan (Table 1). This kind of time delay between the PK and PD parameters has been reported in valsartan ${ }^{17,18}$ and with other antihypertensive agents, such as losartan, ${ }^{18}$ olmesartan, ${ }^{19}$ fimasartan, ${ }^{20}$ and azelnidipine. ${ }^{19}$

The present study had several limitations. Generally, a highest tolerated dose is recommended to be used in the drug-drug interaction study, such that the potential for drugdrug interaction is maximized. In this study, however, the second highest doses for cilnidipine $(10 \mathrm{mg})$ and valsartan $(160 \mathrm{mg}$ ) were evaluated instead, although the label allows up to $20 \mathrm{mg}$, for cilnidipine, ${ }^{21}$ and $320 \mathrm{mg}$, for valsartan. ${ }^{22}$ This was because those doses are prescribed more frequently in a clinical setting than the highest doses. Another limitation was that there was no placebo group in this study. Therefore, the blood pressure-lowering effects found in the present study were not placebo-adjusted. Finally, the maximum blood pressurelowering effects of $\mathrm{ARBs}$ and $\mathrm{CCBs}$ have been reported to occur at 4-8 weeks after the start of treatment. ${ }^{23,24}$ Thus, future studies are warranted, where cilnidipine and valsartan are repeatedly administered and compared with placebo, maybe in patients with hypertension, to confirm the findings of the present study.

\section{Conclusion}

In conclusion, coadministration of cilnidipine and valsartan does not cause a significant PK drug interaction in healthy male subjects and does not adversely affect their blood pressure-lowering effects. Coadministered cilnidipine and valsartan are well tolerated. Future studies, employing multiple administrations in hypertensive patients, are warranted to confirm these results.

\section{Acknowledgments}

This study was supported by a research grant from Ildong Pharmaceuticals, Ltd, Seoul, Korea. Jieon Lee, Dongseong Shin, and Kyungho Jang received training program grants from the Korea Healthcare Technology R\&D Projects, Ministry for Health and Welfare, Republic of Korea (number A070001).

\section{Disclosure}

The authors report no conflicts of interest in this work. 


\section{References}

1. Chobanian AV, Bakris GL, Black HR, et al; National Heart, Lung, and Blood Institute Joint National Committee on Prevention, Detection, Evaluation, and Treatment of High Blood Pressure; National High Blood Pressure Education Program Coordinating Committee. The seventh report of the Joint National Committee on prevention, detection, evaluation, and treatment of high blood pressure: the JNC 7 report. JAMA. 2003;289(19):2560-2572.

2. Meka N, Katragadda S, Cherian B, Arora RR. Combination therapy in hypertension: A focus on angiotensin receptor blockers and calcium channel blockers. Am J Ther. 2010;17(1):61-67.

3. Kim-Mitsuyama S, Ogawa H, Matsui K, Jinnouchi T, Jinnouchi H, Arakawa K. An angiotensin II receptor blocker-calcium channel blocker combination prevents cardiovascular events in elderly high-risk hypertensive patients with chronic kidney disease better than high-dose angiotensin II receptor blockade alone. Kidney Int. 2013;83(1):167-176.

4. Woo KT, Wong KS, Choong HL, Foo MW, Tan HK, Chan CM. Angiotensin receptor blocker and calcium channel blocker combination prevents cardiovascular events in CKD better than high-dose ARB alone. Kidney Int. 2013;84(1):214-215.

5. Mori H, Ukai H, Yamamoto H, et al. Current status of antihypertensive prescription and associated blood pressure control in Japan. Hypertens Res. 2006;29(3):143-151.

6. Brachmann J, Ansari A, Mahla G, Handrock R, Klebs S. Effective and safe reduction of blood pressure with the combination of amlodipine $5 \mathrm{mg}$ and valsartan $160 \mathrm{mg}$ in hypertensive patients not controlled by calcium channel blocker monotherapy. Adv Ther. 2008;25(5):399-411.

7. Minami J, Kawano Y, Makino Y, Matsuoka H, Takishita S. Effects of cilnidipine, a novel dihydropyridine calcium antagonist, on autonomic function, ambulatory blood pressure and heart rate in patients with essential hypertension. Br J Clin Pharmacol. 2000;50(6):615-620.

8. Kario K, Nariyama J, Kido H, et al. Effect of a novel calcium channel blocker on abnormal nocturnal blood pressure in hypertensive patients. J Clin Hypertens (Greenwich). 2013;15(7):465-472.

9. Minami J, Ishimitsu T, Kawano Y, Numabe A, Matsuoka H. Comparison of 24-hour blood pressure, heart rate, and autonomic nerve activity in hypertensive patients treated with cilnidipine or nifedipine retard. J Cardiovasc Pharmacol. 1998;32(2):331-336.

10. Mistry NB, Westheim AS, Kjeldsen SE. The angiotensin receptor antagonist valsartan: a review of the literature with a focus on clinical trials. Expert Opin Pharmacother. 2006;7(5):575-581.

11. Biswas PN, Wilton LV, Shakir SW. The safety of valsartan: results of a postmarketing surveillance study on 12881 patients in England. J Hum Hypertens. 2002;16(11):795-803.
12. Williams JR. Revising the Declaration of Helsinki. World Med J. 2008;54:120-122.

13. Markham A, Goa KL. Valsartan. A review of its pharmacology and therapeutic use in essential hypertension. Drugs. 1997;54(2):299-311.

14. Kanaoka T, Tamura K, Wakui H, et al. L/N-type calcium channel blocker cilnidipine added to renin-angiotensin inhibition improves ambulatory blood pressure profile and suppresses cardiac hypertrophy in hypertension with chronic kidney disease. Int J Mol Sci. 2013;14(8): 16866-16881.

15. Liu XQ, Zhao Y, Li D, Qian ZY, Wang GJ. Metabolism and metabolic inhibition of cilnidipine in human liver microsomes. Acta Pharmacol Sin. 2003;24(3):263-268.

16. Poirier A, Cascais AC, Funk C, Lavé T. Prediction of pharmacokinetic profile of valsartan in humans based on in vitro uptake-transport data. Chem Biodivers. 2009;6(11):1975-1987.

17. Julius S. Long-term potential of angiotensin receptor blockade for cardiovascular protection in hypertension: the VALUE trial. Valsartan Antihypertensive Long-term Use Evaluation. Cardiology. 1999; 91 Suppl 1:S8-S13.

18. Csajka C, Buclin T, Fattinger K, Brunner HR, Biollaz J. Population pharmacokinetic-pharmacodynamic modelling of angiotensin receptor blockade in healthy volunteers. Clin Pharmacokinet. 2002;41(2): $137-152$.

19. Tanigawara Y, Yoshihara K, Kuramoto K, Arakawa K. Comparative pharmacodynamics of olmesartan and azelnidipine in patients with hypertension: a population pharmacokinetic/pharmacodynamic analysis. Drug Metab Pharmacokinet. 2009;24(4):376-388.

20. Lee J, Han S, Jeon S, Hong T, Yim DS. Pharmacokineticpharmacodynamic model of fimasartan applied to predict the influence of a high fat diet on its blood pressure-lowering effect in healthy subjects. Eur J Clin Pharmacol. 2013;69(1):11-20.

21. Takahara A. Cilnidipine: a new generation $\mathrm{Ca}$ channel blocker with inhibitory action on sympathetic neurotransmitter release. Cardiovasc Ther. 2009;27(2):124-139.

22. Philips B, Somer V. American Pharmaceutical Association. Drug Information Handbook for Cardiology. Hudson, OH: Lexi-Comp; 2000.

23. Kondrack R, Mohiuddin S. Valsartan/hydrochlorothiazide: pharmacology and clinical efficacy. Expert Opin Drug Metab Toxicol. 2009;5(9): 1125-1134.

24. Lee H, Kim KS, Chae SC, Jeong MH, Kim DS, Oh BH. Ambulatory blood pressure response to once-daily fimasartan: an 8-week, multicenter, randomized, double-blind, active-comparator, parallel-group study in Korean patients with mild to moderate essential hypertension. Clin Ther. 2013;35(9):1337-1349.
Drug Design, Development and Therapy

\section{Publish your work in this journal}

Drug Design, Development and Therapy is an international, peerreviewed open-access journal that spans the spectrum of drug design and development through to clinical applications. Clinical outcomes, patient safety, and programs for the development and effective, safe, and sustained use of medicines are a feature of the journal, which

\section{Dovepress}

has also been accepted for indexing on PubMed Central. The manuscript management system is completely online and includes a very quick and fair peer-review system, which is all easy to use. Visit $\mathrm{http}: / /$ www.dovepress.com/testimonials.php to read real quotes from published authors. 